УДК 343.533.6

DOI dx.doi.org/10.24866/1813-3274/2019-4/136-152
А. В. Даниловская ${ }^{1}$, Хабаровский государственный университет экономики и права, г. Хабаровск; Дальневосточный федеральный университет,
г. Владивосток, Россия
E-mail: d_a_v@list.ru

\title{
ОСНОВАНИЯ СМЯГЧЕНИЯ И ИСКЛЮЧЕНИЯ УГОЛОВНОЙ ОТВЕТСТВЕННОСТИ ЗА КАРТЕЛИ НА ТОВАРНЫХ РЫНКАХ
}

Аннотащия. Предупреждение и пресечение картелей как одной из угроз национальной безопасности является приоритетным направлением современной конкурентной политики государства. Однако картели на товарных рынках (исключение сговоры на торгах) имеют особую природу, о чём свидетельствуют разное отношение к картелям в отдельные периоды времени, позиции некоторых экономических учений и современные взгляды. Так, представители австрийской школы выступают за отмену борьбы с картелями в принципе. В различных научных источниках встречаются предложения о признании на законодательном уровне экономической целесообразности картельных соглашений в сфере НИОКР, инноваций, при реализации проектов, направленных на модернизацию и структурную перестройку отраслей, о необходимости изменения отношения к картелям, о смягчении государственной политики в отношении соглашений такого рода. Современная антимонопольная политика характеризуется жёстким запретом картелей, заключение которых влечёт уголовную ответственность при наличии всех признаков преступления. Между тем проведённое исследование позволяет сделать вывод о том, что при наличии определённых обстоятельств заключение картеля может быть экономически полезным, а значит юридически обоснованным и оправданным, чему должна при необходимости даваться соответствующая уголовно-правовая оценка. УК РФ содержит необходимые инструменты для учёта многих обстоятельств деяния, со-

\footnotetext{
${ }^{1}$ Анна Владимировна Даниловская, кандидат юридических наук, доцент юридического факультета Хабаровского государственного университета экономики и права, г. Хабаровск; докторант Дальневосточного федерального университета, г. Владивосток, Россия.

Для циитирования: Даниловская А. В. Основания смягчения и исключения уголовной ответственности за картели на товарных рынках // Азиатско-Тихоокеанский регион: экономика, политика и право. 2019. № 4. C. 136-152.
}

(C) Даниловская А. В., 2019 
держащего признаки преступления, при решении вопроса о привлечении к уголовной ответственности за картели.

Ключевые слова: уголовная ответственность, картель, ст. 178 УК РФ «Ограничение конкуренции», основания смягчения наказания, исключение ответственности, крайняя необходимость, экономический кризис.
Anna V. Danilovskaya ${ }^{1}$, Khabarovsk State University of Economics and Law, Khabarovsk; Far Eastern Federal University, Vladivostok, Russia E-mail: d_a_v@list.ru

\section{GROUNDS FOR MITIGATION AND EXCLUSION OF CRIMINAL LIABILITY FOR CARTELS IN COMMODITY MARKETS}

Abstract. Prevention and suppression of cartels, as one of the threats to the national security, is a priority of the modern competitive policy of the state. However, cartels in commodity markets (with the exception of collusions at auction) have a special nature, as evidenced by different attitudes to cartels in certain periods of time, the positions of some economic doctrines and modern views. Therefore, representatives of the Austrian school are in favor of abolishing the fight against cartels in principle. In various scientific sources, there are proposals to recognize at the legislative level the economic feasibility of cartel agreements in the field of $\mathrm{R} \& \mathrm{D}$, innovation, in the implementation of projects aimed at modernizing and restructuring industries, the need to change the attitude to cartels, and to soften state policy in relation to such agreements. Modern antitrust policy is characterized by a strict prohibition of cartels, the conclusion of which entails criminal liability if there are all signs of a crime. Meanwhile, the study allows us to conclude that in certain circumstances, the conclusion of a cartel can be economically useful, and therefore legally justified, which should, if necessary, be given an appropriate criminal legal assessment. The Criminal Code of the Russian Federation contains the necessary tools to take into account many circumstances of an act containing signs of a crime when deciding whether to prosecute cartels.

Keywords: criminal liability, cartel, article 178 of the criminal code of the Russian Federation "Restriction of competition", grounds for mitigation of punishment, exclusion of liability, extreme necessity, economic crisis.

\footnotetext{
${ }^{1}$ Anna V. Danilovskaya, Candidate of Law, Associate Professor of the Faculty of Law, Khabarovsk State University of Economics and Law, Khabarovsk; Doctoral student, Far Eastern Federal University, Vladivostok, Russia.

For citing: Danilovskaya A. V. Grounds for mitigation and exclusion of criminal liability for cartels in commodity markets // PACIFIC RIM: Economics, Politics, Law. 2019. No 4. P. 136-152.
} 
Отношение к картелям было всегда неоднозначным. История антимонопольной политики в отдельных странах и в разные периоды свидетельствует о времени принудительной картелизации, разрешения экспортных картелей, создания с разрешения уполномоченных органов государства временных картелей для помощи пострадавшим от кризиса отраслям экономики, ослабления запретов на картели в условиях кризиса и ограничения на применение антимонопольных запретов, включая запреты на картели в отдельных сферах $[1$, с. $103 ; 2$, с. 82-86; 3]. Такие подходы объясняются, с одной стороны, соответствующими политическими, экономическими и правовыми позициями относительно картелей, с другой - значением картелей для экономики страны в конкретный период времени в связи с их возможными положительными эффектами. Предложения об изменении существующей антимонопольной политики в сторону большей лояльности встречаются и на современном этапе экономического и правового развития $[1$, с. $103 ; 2$, с. $82-86 ; 4$, с. $35 ; 5$, с. $91-$ $100 ; 6$, с. 53-64], который в России характеризуется жёстким запретом картелей без учёта каких-либо обстоятельств. Соглашения между конкурентами запрещены, если они привели или могут привести к последствиям, описанным в ч. 1 ст. 11 Федерального закона «О защите конкуренции», связанным с ценовой политикой, разделом рынка, прекращением производства и бойкотом отдельных продавцов или покупателей. Уголовная ответственность за картель установлена ст. 178 УК РФ «Ограничение конкуренции».

Противоречивость картелей, их жёсткий запрет явились поводом для проведения отдельного исследования возможности применения тех положений УК РФ, которые предусматривают основания смягчения ответственности, освобождения от неё или же её исключения, к лицам, в действиях которых усматриваются признаки указанного преступления, но чей картель был заключен при определённых, исключительных обстоятельствах. Результат такого исследования позволяет сделать вывод о наличии двух факторов - позитивного и негативного характера, детерминирующих появление картелей, которые могут стать основаниями как смягчения ответственности, так и освобождения от неё или исключения её вовсе при наличии необходимых правовых условий.

Значение картеля определяется целями, ради которых соглашение заключается, и способами их достижения. Несмотря на то, что существует множество видов картелей, общепризнано, что их целью является получение максимальной (дополнительной) прибыли путём ограничения конкуренции.

Однако представляется, что это не всегда так - спор об этом существовал в науке ещё в начале $\mathrm{XX}$ в. Некоторые из картелей, как видится из существа отдельных объединений хозяйствующих субъектов, преследуют несколько иные цели, чем просто получение прибыли, и поэтому появляются для решения задач другого рода. Так, среди задач экспортных картелей отмечаются: повышение конкуренто- 
способности продукции на мировых рынках; поддержка деятельности компаний за счёт зарубежных заказов при ограниченном спросе на внутреннем рынке. В связи с тем, что такая деятельность хозяйствующих субъектов способствует единой государственной политике на международных рынках, защите национальных интересов государств-экспортёров, повышению доходной части бюджета за счёт экспортных пошлин, во многих странах экспортные картели признаны законными и выведены из-под действия антимонопольного законодательства [8, с. 269].

Отраслевые ассоциации выполняют такие позитивные функции, как ознакомление членов ассоциации с технологическими и иными достижениями в отрасли, информационное просвещение, совместная подготовка и обучение персонала, повышение квалификации, проведение совместных исследований рынка, спонсорских мероприятий [8, с. 269], стандартизация продукции.

Выделяют также другие картели, деятельность которых может быть признана не только не опасной, но и полезной обществу, например, картели, обладающие небольшой долей рынка, а также картели, созданные для освоения нового рынка [9], что нашло отражение в ряде антимонопольных законов, например, в законах Республики Корея [10], КНР [11], ФРГ [12], Великобритании [13], Франции [14].

Вышеизложенное можно оценить как позитивные факторы появления картелей, которые определяются перспективными целями деятельности хозяйствующих субъектов, связанными с развитием отрасли и повышением общественного благосостояния.

При решении вопроса о привлечении к уголовной ответственности за заключение и реализацию такого рода картелей на товарном рынке следовало бы учитывать положительные явления, возникшие именно в связи с существованием конкретного картеля. Явный позитивный характер значимых для общества экономических последствий картеля на товарном рынке может свидетельствовать об отсутствии общественной опасности деяния как таковой или её незначительности. Полагаем, вопрос об уголовной ответственности в таких случаях может решаться с позиции анализа общих признаков деяния как преступления согласно ст. 14 УК РФ. В случае превышения негативных последствий картеля над позитивными, при назначении наказания, указанные обстоятельства должны учитываться в качестве смягчающих в соответствии со ст. 61 или иных, перечисленных в ст. 64 УК РФ.

Другой вариант решения вопроса об ответственности за заключение картеля на товарном рынке видится в специальном основании освобождения в связи с экономически обоснованной полезностью картеля. Данное предложение могло бы быть реализовано путём включения соответствующей правовой нормы в примечание к ст. 178, в котором содержатся основания освобождения от ответственности за картель.

Между тем, обратим внимание на картели структурных кризисов («кризисные» картели), появление которых предопределено негативными факторами эко- 
номического характера. Ими называют соглашения, которые должны обеспечить безболезненное свёртывание производственных мощностей при устойчивом, не обусловленном конъюнктурой сокращении сбыта. Такого рода картельные соглашения заключаются обычно во время циклических спадов производства, в условиях, когда баланс спроса и предложения на продукцию отрасли резко нарушен (имеются большие запасы непроданной продукции), цены падают ниже среднеотраслевой себестоимости и значительное число предприятий отрасли вынуждены прекратить производство. В этом случае компании согласовывают между собой масштабы снижения производства и недогрузки мощностей до тех пор, пока избыток продукции не будет продан [15, с. 104]. Такие картели разрешены, например, в Японии - соглашения заключаются на период резких спадов производства и действуют определённый срок с возможностью продления [16, с. 240]. Известно, что в 1950-1970 гг. легальные картели помогли выйти из затяжного кризиса японской чёрной металлургии, судостроению, химической, нефтеперерабатывающей и угледобывающей отраслям [16, с. 243]. Кризисные картели разрешены в Европе [16, c. 244], КНР, Республике Корея.

В российском законодательстве не существует оснований для каких-либо исключений из общего запрета на картели. Не отрицая необходимости ответственности, в том числе уголовной, за заключение картеля, полагаем важным учитывать обстоятельства, которые привели к его заключению на товарном рынке. В условиях, с одной стороны, экономического кризиса ${ }^{1}$, когда фиксируется спад производства, с другой - острой конкурентной борьбы, хозяйствующие субъекты вынуждены объединять свои усилия в целях избежания неблагоприятных последствий. В их числе - вынужденное прекращение деятельности, включая банкротство, и сопутствующие этому негативные факторы как экономического, так и социального характера, связанные, например, с неуплатой налогов, иных обязательных выплат, увольнением работников.

Правовые нормы, предусматривающие особенности исключения ответственности лиц за деяния, повлекшие причинение вреда в особых условиях, представляют собой давно устоявшиеся и существующие в разных отраслях законодательства институты. С правовой позиции, заключение в условиях кризиса картеля по своему характеру представляет собой деяние, близкое по сути крайней необходимости. При этом, фактически, поведение лиц - представителей хозяйствующих субъектов, заключивших картель, может полностью соответствовать признакам, свойственным почти всем обстоятельствам, исключающим преступность деяния, перечисленным в гл. 8 УК РФ: 1) осознание лицом общественной полезности или социальной целесообразности причинения вреда, причинённый вред является вынужденным; 2) по-

\footnotetext{
${ }^{1}$ При этом под экономическим кризисом справедливо понимать внешние проблемы экономического характера, а не внутренние, обусловленные неэффективным управлением.
} 
ведение лица является осознанным, волевым и целенаправленным; 3) деяние является общественно полезным или социально допустимым; 4) рассматриваемое поведение осуществляется в особой обстановке и при наличии соответствующего основания причинения вреда; 5) поведение соответствует определённым условиям правомерности причинения вреда [17, с. 31-33].

Особо значимым, в свете данного исследования, является такой признак, как общественная полезность и социальная допустимость картеля. Так, сохранение хозяйствующего субъекта как экономического агента, участвующего в процессах производства, распределения, обмена и потребления материальных благ, налогоплательщика, работодателя, имеющего социальную ответственность, обусловливает признание заключённого в условиях кризиса картеля не только социально допустимым, но и общественно полезным.

Факт общественной полезности и социальной допустимости картеля в определённых условиях подтверждается и отдельными современными экономическими исследованиями [4, с. 35]. Причём, речь может идти не только о кризисных картелях, но и экспортных, в сфере НИОКР и некоторых других.

Рассматривая условия крайней необходимости, характеризующие опасность и само деяние, можно сделать вывод о свойственности их критериев экономическим кризисам и соответствующему поведению лиц, направленному на заключение и реализацию картеля. Опасность экономических кризисов не вызывает сомнений она носит действительный характер и всегда будет угрожать охраняемым интересам, является наличной и реальной, причём, как правило, имеет длительный временной характер. При этом под угрозу попадают правомерные экономические интересы государства, юридических лиц, граждан, гарантии и защита которых предусмотрены Конституцией РФ. К перечисленным лицам относятся и хозяйствующие субъекты, заключившие картель на товарном рынке, которые избрали именно такой способ защиты своих прав.

В свою очередь, такие условия правомерности поведения, как направленность деяния на защиту охраняемых интересов, невозможность осуществления защиты иным способом без причинения вреда охраняемым законом интересам, своевременность защиты, причинение вреда третьим лицам, имеют место при анализе поведения представителей хозяйствующих субъектов в рассматриваемой ситуации. При этом причинение вреда потребителям, организациям, государству обусловлено ограничением участниками картеля конкуренции, которое выступает как способ осуществления защиты экономических прав в условиях неопределённости в целях снижения её негативного эффекта.

Таким образом, условия, характеризующие опасность при крайней необходимости, и условия, определяющие само деяние, причиняющее вред во избежание этой самой опасности, могут полностью соответствовать нестабильной и опасной 
ситуации экономического кризиса, спровоцированному им поведению, направленному на заключение картеля, и, как следствие, причинение путём ограничения конкуренции вреда потребителям, другим хозяйствующим субъектам, государству. Анализ таких условий и соответствующего им поведения субъектов выводит на вопрос о справедливости распространения жёсткого запрета на кризисные картели, в то время как такого рода соглашения являются, практически, естественным способом защиты частных интересов, основанном на объединении усилий для противостояния общей опасности.

Между тем, вопрос применения института крайней необходимости к преступлениям в сфере экономической деятельности редко поднимается в науке [18, с. $43-$ 57], но не является забытым в правоприменении, правда, в основном при рассмотрении дел по налоговым преступлениям [19, 20]. Между тем, вопрос применения института крайней необходимости к преступлениям в сфере экономической деятельности редко поднимается в науке [18, с. 43-57], хотя и не является забытым в правоприменении, правда, в основном при рассмотрении дел по налоговым преступлениям $[19,20]$ и только с недавнего времени. Последнее обусловлено разъяснениями Конституционного Суда РФ, который указал на необходимость при квалификации деяний учитывать возможность причинения вреда охраняемым уголовным законом интересам в состоянии крайней необходимости в своём определении от 24.06.2014 г. №1346 «Об отказе в принятии к рассмотрению жалобы гражданина Максименко Романа Викторовича на нарушение его конституционных прав статьёй 199.2 Уголовного кодекса Российской Федерации» [21].

Экономический кризис как основание освобождения от ответственности по гражданским и административным делам нередко становится предметом рассмотрения арбитражными судами - в решениях поднимается вопрос о возможности признания экономических кризисов обстоятельством непреодолимой силы. Арбитражная практика по данному вопросу является противоречивой - есть примеры решений, признающих экономические (финансово-экономические) кризисы, колебания курса валюты таковым обстоятельством [22-25], и есть противоположные [26-27]. С 2015 г. последних стало больше в связи с принятием Положения о порядке свидетельствования Торгово-промышленной палатой Российской Федерации обстоятельств непреодолимой силы (форс-мажор), согласно п. 1.3 которого финансово-экономический кризис не является непреодолимой силой [28], ставшего основой соответствующих выводов судей [29].

Между тем, развитие сферы предпринимательской деятельности, а значит увеличение количества хозяйствующих субъектов с неизбежностью ведёт не только к обострению конкурентной борьбы, но и к увеличению рисков быть подвергнутыми экономическим кризисам. Как показывает анализ экономической литературы, предотвратить экономические кризисы волевыми усилиями и в рамках моделей, 
предложенных экономической теорией [30, с. 11-17, 33, с. 24-33], признанных экономистами по итогам последних лет провалами экономической науки и политики многих стран [31, с. 117], невозможно. Действующая система управления экономикой оказалась неспособной своевременно и эффективно реагировать на новые вызовы и угрозы [32, с. 198].

В связи с изложенным представляется, что решение вопроса об уголовной ответственности, включая справедливость и целесообразность мер наказания за картель, должно отражать взвешенную оценку всех обстоятельств на основе положений как Общей, так и Особенной частей УК РФ. Существующие уголовноправовые правовые средства позволят минимизировать или исключить вовсе неблагоприятные последствия привлечения к уголовной ответственности за картели, появление которых может иметь благоприятные для экономики результаты.

\section{Список литературы}

1. Баринов, Н. А. Антимонопольное законодательство Российской Федерации (вопросы теории и практики) / Н. А. Баринов, М. Ю. Козлова. - Волгоград : Изд-во Волгоградского государственного университета, 2001. - 190 с.

2. Новиков, В. В. Перекрутили гайки: российский антитраст в конце своего первого двадцатилетия // Экономическая политика. - 2010. - № 2. - С. 82-86.

3. Мильнер, Б. 3. Теория организации / Б. З. Мильнер. - Москва : ИНФРА-М, 2000. - URL: http://www.bibliotekar.ru/teoriya-organizacii/136.htm (дата обращения: 18.06.2018).

4. Клюзина, С. В. Монополия и локальная монополия как ее тип: история вопроса, методология, теория и практика : автореф. дис. ... д-ра. экон. наук / С. В. Клюзина. - Москва, 2005. - 424 с.

5. Кизилов, В. В. К вопросу о необходимости отмены антимонопольного законодательства / В. В. Кизилов, В. В. Новиков // Закон. - 2008. - № 2. - С. 91-100.

6. Андреященко, Е. К вопросу о методологии анализа картельных соглашений / Е. Андреященко, А. Заздравных // Вопросы экономики. - 2014. - № 9. - С. 53-64.

7. Венедиктов, А. В. Избранные труды по гражданскому праву. Т. 1 : Слияние акционерных компаний. - URL : http://sud09.ru/bibliot/Elib/1618.html (дата обращения: 26.02.2018).

8. Князева, И. В. Антимонопольная политика в России : учеб. пособие для студентов вузов, обучающихся по специальности «Национальная экономика» / И. В. Князева. - Москва : Омега-Л, 2006. - 505 с.

9. Энциклопедия экономиста. - URL: http://www.grandars.ru/college/ekonom ika-firmy/kartel.html (дата обращения: 07.02.2020).

10. Monopoly regulation and fair trade act (Enforcevent date 29.03.2016: Act № 14137, 29.03.2016) // Комиссия по справедливой торговле Республики Корея : 
офиц. сайт. - URL: http://www.ftc.go.kr/solution/skin/doc.html?fn=abe6ebfcff cd366c32a8cb91035bdbee5ad625cdf007b29f88891153490137d1\&rs=/fileupload/data/res ult/BBSMSTR_000000002411/\# (дата обращения: 03.11.2019).

11. Закон КНР «О противодействии монополиям»: принят на 29 заседании Постоянного комитета Всекитайского собрания народных представителей 10 созыва 30.08.2007 г. // Комитет по коммерческой работе со странами СНГ Китайскоевропейской ассоциации технико-экономического сотрудничества : офиц. сайт. URL: http://www.cniru.ru/gjzlk/shownews.php?lang=ru\&id=42 (дата обращения: 10.10.2019).

12. Gesetz gegen Wettbewerbsbeschränkungen in der Fassung der Bekanntmachung vom 26. Juni 2013 // Министерство юстиции и защиты прав потребителей ФРГ : офиц. сайт. - URL: http://www.gesetze-im-internet.de/gwb/index.html (дата обращения: 05.12.2019).

13. Competition Act 1998 // Правительственный веб-сайт Великобритании. URL: http://www.legislation.gov.uk/ukpga/1998/41/contents (дата обращения: 10.12.2019).

14. Code de commerce (version consolidée au 22 septembre 2018) // Официальный сайт ВОИС. - URL: https://wipolex.wipo.int/en/text/485951 (дата обращения: 15.12.2019).

15. Корпоративное право: учеб. пособие для студентов вузов, обучающихся по специальности «Юриспруденция» / под ред. И. А. Еремичева, Е. А. Павлова. 3-е изд. перераб. и доп. - Москва : ЮНИТИ-ДАНА, Закон и право, 2015. - 439 с.

16. Станковская, И. К. Экономическая теория: Полный курс MBA / И. К. Станковская, И. А. Стрелец. - М. : Рид Групп, 2016. - (Российское бизнесобразование). 480 с.

17. Орешкина, Т. Ю. Обстоятельства, исключающие преступность деяния: учебное пособие для магистрантов / Т. Ю. Орешкина ; отв. ред. А. И. Рарог. Москва : Проспект, 2016. - 112 с.

18. Яни, П. С. Крайняя необходимость: непреступный вред экономического преступления // Закон. - 2000. - № 7. - С. 43-57.

19. Апелляционное постановление по уголовному делу № 22-670/2019 от 16.04.2019 г. Доступ с официального сайта суда Хабаровского края. - URL: https://kraevoy--hbr.sudrf.ru/modules.php?name=sud_delo\&srv_num=1\&name_op =doc\&number=15356907\&delo_id=4\&new=4\&text_number=1 (дата обращения: 07.02.2020).

20. Апелляционное постановление по делу № 22-963 от 18.09.2018 г. Доступ с официального сайта Сахалинского областного суда. - URL: https://oblsud-sah.sudrf.ru/modules.php?name=sud_delo\&srv_num=1\&name_op=doc\&number=12767 24\&delo_id=4\&new=4\&text_number=1 (дата обращения: 07.02.2020). 
21. Определение Конституционного Суда РФ от 24.06.2014 г. №1346 «Об отказе в принятии к рассмотрению жалобы гражданина Максименко Романа Викторовича на нарушение его конституционных прав статьей 199.2 Уголовного кодекса РФ» // Правосудие: судебная практика России. - URL: http://ksportal.garant .ru:8081/SESSION/PILOT/main.htm (дата обращения: 15.06.2019). - Режим доступа: для авториз. пользователей.

22. Постановление ФАС Поволжского округа от 16.11.1999 г. по делу № А722217/99-3 165. - Режим доступа: СПС Гарант (дата обращения 26.10.2019).

23. Постановление ФАС Московского округа от 3.11.1999 г. по делу № КГА40/3612-99. - Режим доступа: СПС Гарант (дата обращения 26.10.2019).

24. Постановление Десятого арбитражного апелляционного суда от 4.09.2009 г. по делу № A41-13282/09. - URL: https://kad.arbitr.ru/ (дата обращения: 22.03.2019). - Режим доступа: по подписке.

25. Постановление Тринадцатого арбитражного апелляционного суда от 23.10.2009 г. по делу №A56-24425/2009. - URL: https://kad.arbitr.ru/ (дата обращения: 22.03.2019). - Режим доступа: для авториз. пользователей.

26. Определение ВАС РФ от 28.04.2012 г. № ВАС-4874/12 по делу № А1212792/2011. - Режим доступа: СПС Гарант (дата обращения 26.10.2019).

27. Постановление ФАС Московского округа от 24.06.2011 г. № КГ-А41/579311 по делу № A-41-25302/10. - Режим доступа: СПС Гарант (дата обращения 26.10.2019).

28. Положение о порядке свидетельствования Торгово-промышленной палатой Российской Федерации обстоятельств непреодолимой силы (форс-мажор) : приложение к постановлению Правления Торгово-промышленной палаты РФ от 23 декабря 2015 г. № 173-14. - Режим доступа: СПС ГАРАНТ (дата обращения 22.03.2019).

29. Решение Арбитражного суда г. Москвы от 25.05.2016 г. по делу № А4047328/2016. - Режим доступа: СПС Гарант (дата обращения 28.10.2019).

30. Куклина, Л. Н., Пономарева С. И. Мировой экономический кризис и модели посткризисного развития: макроэкономический анализ / Л. Н. Куклина, С. И. Пономарева // Известия УрГЭУ. - 2012. - № 1 (39). - С. 11-17.

31. Мартишин, Е. М. Современные экономические парадигмы и развитие экономической теории // Экономическая наука современной России. - 2011. - № 4 (55). - C. 117-122.

32. Российская экономика в 2015-2017 годах / А. Френкель, Б. Тихомиров, Я. Сергиенко, Л. Рощина // Экономическая политика. 2016. Т. 11. № 5. С. 198-233.

33. Андреев, М. Ю. Тенденции развития макроэкономических моделей / М. Ю. Андреев, А. В. Полбин // Управленческое консультирование. 2019.№ 2. C. 24-33. 


\section{References}

1. Barinov N. A., Kozlova M. Yu. Antimonopol'noe zakonodatel'stvo Rossiiskoi Federatsii (voprosy teorii i praktiki) [Antimonopoly legislation of the Russian Federation (theory and practice)]. Volgograd: Publishing House of Volgograd State University, 2001. $190 \mathrm{p}$.

2. Novikov V. V. Perekrutili gaǐki: rossǐskiı̌ antitrast v kontse svoego pervogo dvadtsatiletiya [Tightened the nuts: Russian antitrust at the end of its first twenty years]. Ekonomicheskaya politika, 2010, no. 2, pp. 82-86.

3. Milner B. Z. Teoriya organizatsii [Theory of organization]. Moscow: INFRA-M, Publ. 2000. Available at: http://www.bibliotekar.ru/teoriya-organizacii/136.htm (accessed 18 June 2018).

4. Klyuzina S. V. Monopoliya i lokal'naya monopoliya kak ee tip: istoriya voprosa, metodologiya, teoriya i praktika [Monopoly and local monopoly as its type: history, methodology, theory and practice]. Dr. diss.(Econ. Sci). Synopsis. M., 2005. 424 p.

5. Kizilov V. V., Novikov V. V. K voprosu o neobkhodimosti otmeny antimonopol'nogo zakonodatel'stva [On the issue of the need to repeal antitrust laws]. Zakon, 2008, no. 2, pp. 91-100.

6. Andreyashchenko E., Zazdravnykh A. K voprosu o metodologii analiza kartel'nykh soglashenii [On the question of the methodology of the analysis of cartel agreements]. Voprosy ekonomiki, 2014, no. 9, pp. 53-64.

7. Venediktov A. V. Izbrannye trudy po grazhdanskomu pravu.Tom 1. Sliyanie aktsionernykh kompanii [Selected works on civil law.Vol. 1 Merger of joint stock companies]. Available at: http://sud09.ru/bibliot/Elib/1618.html (accessed 26 February 2018).

8. Knyazeva I. V. Antimonopol'naya politika v Rossii [Antitrust policy in Russia: textbook. A manual for university students enrolled in the specialty «National Economics»]. Moscow: Omega-L Publ, 2006. 550 p.

9. Encyclopedia of an economist. Available at: http://www.grandars.ru/college/ ekonomika-firmy/kartel.html (accessed 7 February 2020). (In Russian).

10. Monopoly regulation and fair trade act (Enforcevent date 03/29/2016: Act No. 14137, 03/29/2016). Access from the official website of the Fair Trade Commission of the Republic of Korea. Available at: http://www.ftc.go.kr/solution/skin/doc.html? $\mathrm{fn}=$ abe6ebfcffcd366c32a8cb91035bdbee5ad625cdf007b29f88891153490137d1\&rs=/fileu pult_BSata/ (accessed 3.11.2019).

11. The PRC Law "On Countering Monopolies»: adopted at the 29th meeting of the Standing Committee of the All-China Assembly of People's Representatives of the 10th convocation on 08/30/2007. Access from the official website of the Committee on Commercial Work with the CIS Countries of the Sino-European Association of Technical and Economic Cooperation. Available at: http://www.cniru.ru/gjzlk/shownews.php?lang $=$ ru\&id=42 (accessed 10.10.2019). (In Russian). 
12. Gesetz gegen Wettbewerbsbeschränkungen in der Fassung der Bekanntmachung vom 26. Juni 2013. Access from the official website of the Ministry of Justice and Consumer Protection of Germany. Available at: http://www.gesetze-iminternet.de/gwb/index.html (accessed 5 December 2019). (In Germany).

13. Competition Act 1998. Access from the Government website of the UK. Available at: http://www.legislation.gov.uk/ukpga/1998/41/contents (accessed 10 December 2019).

14. Code de commerce (version consolidée au 22 septembre 2018). Access from the official WIPO website. Available at: https://wipolex.wipo.int/en/text/485951 (accessed 15 December 2019).

15. Eremichev I. A., Pavlov E. A., eds. Korporativnoe pravo [Corporate law: textbook. manual for university students enrolled in the specialty "Jurisprudence"]. 3rd ed. reslave. and add. Moscow : UNITY-DANA Publ., 2015.443 p.

16. Stankovskaya I. K., Strelets I. A. Ekonomicheskaya teoriya: Polnyi kurs MVA [Economic theory: Full MBA course]. - Moscow: Reed Group, 2016. 480 p. (Russian business education). 17. Oreshkina T. Yu. Obstoyatel'stva, isklyuchayushchie prestupnost' deyaniya [Circumstances precluding crime acts: a textbook for undergraduates]. Moscow: Prospect Publ., 2016. 112 p.

18. Jani P. S. Krainyaya neobkhodimost': neprestupnyi vred ekonomicheskogo prestupleniya [Extreme need: the indestructible harm of an economic crime]. Zakon, 2000, no. 7, pp. 43-57.

19. Appeal resolution in criminal case No. 22-670/2019 of 04.16.2019. Access from the official site of the Khabarovsk Territory court. Available at: https://kraevoy-hbr.sudrf.ru/modules.php?name=sud_delo\&srv_num $=1 \&$ name_op $=$ doc $\&$ number $=$ $15356907 \&$ delo_id $=4 \&$ new $=4 \&$ text_number $=1$ (accessede 7 February 2020). (In Russian).

20. Appeal resolution in the case No. 22-963 of September 18, 2018. Access from the official website of the Sakhalin Regional Court. Available at: https://oblsud-sah.sudrf.ru/modules.php?name=sud_delo\&srv_num=1\&name_op= doc $\&$ number $=$ $1276724 \&$ delo_id $=4 \&$ new $=4 \&$ text_number $=1$ (accessed 7 February 2020). (In Russian).

21. The determination of the Constitutional Court of the Russian Federation of June 24, 2014 No. 1346 «On the refusal to accept for consideration a complaint of a citizen Maksimenko Roman Viktorovich on violation of his constitutional rights by Article 199.2 of the Criminal Code of the Russian Federation». Available at: http://ksportal.garant.ru:8081/SESSION/PILOT/main.htm (accessed 15 June 2019). (In Russian).

22. Decision of the Federal Antimonopoly Service of the Volga Region of 11.16.1999 in the case No. A72-2217/99-z 165. Available at: Reference and legal system Garant (accessed 26 October 2019). (In Russian). 
23. Resolution of the FAS of the Moscow District on November 3, 1999 in case No. KG-A40/3612-99. Available at: Reference and legal system Garant (accessed 26 October 2019). (In Russian).

24. The decision of the Tenth Arbitration Court of Appeal dated September 4, 2009 in case No. A41-13282/09. Available at: https://kad.arbitr.ru (accessed 22 March 2019). (In Russian).

25. The ruling of the Thirteenth Arbitration Court of Appeal dated 10.23.2009 in the case No. A56-24425/2009. Available at: https://kad.arbitr.ru/ (accessed 22 March 2019). (In Russian).

26. Determination of the Supreme Arbitration Court of the Russian Federation of April 28, 2012 No. VAS-4874/12 in the case No. A12-12792/2011. Available at: Reference and legal system Garant (accessed 26 October 2019). (In Russian).

27. Decision of the FAS of the Moscow District dated June 24, 2011 No. KG-A41 / 5793-11 in the case No. A-41-25302/10. Available at: Reference and legal system Garant (accessed 26 October 2019). (In Russian).

28. Regulation on the procedure for witnessing force majeure circumstances by the Chamber of Commerce and Industry of the Russian Federation (force majeure): Appendix to Resolution of the Board of the Chamber of Commerce and Industry of the Russian Federation dated December 23, 2015 No. 173-14. Available at: Reference and legal system Garant (accessed 26 October 2019). (In Russian).

29. Decision of the Moscow Arbitration Court of May 25, 2016 in case No. A4047328/2016. Available at: Reference and legal system Garant (accessed 26 October 2019). (In Russian).

30. Kuklina L. N., Ponomareva S. I. Mirovoi ekonomicheskii krizis i modeli postkrizisnogo razvitiya: makroekonomicheskii analiz [The world economic crisis and models of post-crisis development: macroeconomic analysis]. Izvestiya Ural'skogo gosudarstvennogo ekonomicheskogo universiteta, 2012, no. 1 (39), pp. 11-17.

31. Martishin E. M. Sovremennye ekonomicheskie paradigmy i razvitie ekonomicheskoi teorii [Modern economic paradigms and the development of economic theory]. Ekonomicheskaya nauka sovremennoi Rossii, 2011, no. 4 (55), pp. 117-122.

32. Frenkel A., Tikhomirov B., Sergienko Y., Roshchina L. Rossiiskaya ekonomika v 2015-2017 godakh [Russian economy in 2015-2017]. Ekonomicheskaya politika, 2016, vol. 11, no. 5, pp. 198-233.

33. Andreev M. Yu., Polbin A. V. Tendentsii razvitiya makroekonomicheskikh modelei [Trends in the development of macroeconomic models]. Upravlencheskoe konsul'tirovanie, 2019, no. 2, pp. 24-33. 